\title{
A FIFA, a Democracia e a Soberania: tensões e paradoxos
}

\section{FIFA, Democracy and Sovereignty: tensions and paradoxes}

\author{
Maria Fernanda Salcedo Repolês \\ Universidade Federal de Minas Gerais, Belo Horizonte - MG, Brasil
}

Francisco de Castilho Prates

Universidade Federal de Minas Gerais, Belo Horizonte - MG, Brasil

Resumo: O artigo parte das declarações de dirigentes da FIFA no contexto das manifestações de junho de 2013, segundo as quais a democracia representaria obstáculo para a realização da Copa do Mundo. Busca-se analisar ainda o suposto "território FIFA" na Lei Geral da Copa. O objetivo é refletir sobre esses dois aspectos a partir das tensões geradas na modernidade entre a realização das promessas de soberania e de democracia e as pressões advindas das forças de mercado notadamente volúveis e imprevisíveis. As manifestações políticas podem ser entendidas como reação à privatização da esfera pública e a lembrança de que a fixação de "territórios" pode também ser oportunidade de encontro e de exercício do dissenso.

Palavras-chave: FIFA. Democracia Constitucional. Soberania. Legitimidade. Liberdade de Manifestação. Liberdade de Expressão.
Abstract: The article's starting point is the statement made by FIFA's chairmen during protests in Brazilian cities, in June 2013, according to which democracy is an obstacle to the organization of the World Cup. Secondo of all, an analysis of a supposed "FIFA territory" introduced by the "World Cup General Statute" is made. The aim is to think of these two aspects through the tensions of Modernity, between the effectiveness of sovereignty and democracy understood as promises and the pressures of the market forces notably volatile and unpredictable. Thus, the political protests can be understood as the reaction to the privatization of public sphere and as a remainder that the fixation of "territories" can also be an opportunity to encounter and to exercise dissent.

Keywords: FIFA. Constitutional Democracy. Sovereignty. Legitimacy. Freedom of Manifestation. Freedom of Speech.

Recebido em: 04/09/2013

Revisado em: 18/03/2015

Aprovado em: 30/04/2015 


\section{Introdução}

Na medida em que o século XXI avança parece que as promessas da Modernidade conflitam com eventos históricos que caminham contra a sua realização. A democracia e a soberania como parte dessas promessas desvendam mais paradoxos do que certezas. Os paradoxos emergem de contrários que convivem ao invés de se excluírem mutuamente, ou seja, em um mundo cada vez mais marcado por incertezas e riscos, as instituições, inclusive as jurídicas, tentam se reafirmar como princípios e bases da própria sociedade que os questiona e, em incontáveis vezes, até nega-os.

Em outras palavras,

[...] as sociedades contemporâneas são extremamente complexas, e tal complexidade importa no surgimento cada vez maior de demandas que exigem tomada de decisões, tanto políticas, quanto jurídicas. Em meio a esta complexidade, termos aparentemente simples, como "lei" ou "direito" perdem seu sentido aparente e se tornam tão incertos quanto o cenário que os abriga. (KOZICKI, 2005, p. 129)

Nesse contexto, parece ter razão o diagnóstico de Zygmunt Bauman de que poder e política aparentam se separar e, enquanto o poder tende a se afastar em direção a um espaço global politicamente desorganizado, a política tende a permanecer local, gerando tensões. Assim, democracia e soberania como promessas da Modernidade se tornam, paradoxalmente, "[...] um playground para as forças de mercado, notoriamente volúveis e inerentemente imprevisíveis”. (BAUMAN, 2007, p. 8)

Sendo assim, procurar-se-á, neste artigo, trabalhar alguns desses paradoxos, das constitutivas tensões que gravitam e envolvem a construção do sentido de democracia e de soberania em cenários conflituosos e fragmentários. Para tanto, valer-se-á, ainda que sucintamente, de certo eventos ocorridos no Brasil, no ano de 2013, por ocasião da denominada Copa das Confederações, haja vista que durante este evento teste, prévio à Copa do Mundo de 2014, o país foi sacudido por uma onda de inesperados protestos sociais, os quais levaram multidões às ruas de todo o Brasil. 
Estas manifestações, de início pacíficas, foram, paulatinamente, assumindo dimensões de violência contestatória, nas quais, os alvos mais visados eram, além do sistema bancário, aquelas empresas e empreendimentos vinculados tanto à Copa das Confederações quanto à Copa do Mundo, as quais têm em comum serem organizadas e concretizadas por uma organização privada supranacional, a Federação Internacional de Futebol (FIFA). Isto é, esses protestos permitiram o emergir, entre outros pontos, de uma série de indagações a respeito do significado e do âmbito normativo de soberania estatal diante dos direitos fundamentais dos indivíduos e coletividades.

Em razão dessas massivas manifestações, Jerome Valcke e Joseph Blater, altos representantes da FIFA, expuseram um ponto de vista que merece ser problematizado, qual seja: que um espaço democrático seria um embaraço, um empecilho a acontecimentos como os que a FIFA patrocina, já que a ausência de um centro inquestionável de poder dificultaria a tomada de decisões necessárias à realização destes últimos, por exemplo, a Copa do Mundo de Futebol.

Ora, foi com o intuito de realizar as medidas exigidas pela FIFA, que foi editada e promulgada a chamada Lei Geral da Copa (Lei n. 12.663/2012), a qual previu o que ficaria conhecido como o "território FIFA" que delimitava uma área de dois quilômetros de zona econômica exclusiva, mas que acabou sendo traduzida, pelo aparato de segurança pública, ainda mais diante das citadas manifestações, como um espaço não aberto ao público, sendo acessível apenas aos consumidores e empreendedores qualificados pela FIFA.

Em suma, essa complexa situação desvelou alguns paradoxos, como já dito, pois protestos fundados no exercício, constitucionalmente garantido, da liberdade de expressão, que levantaram bandeiras plurais, entre elas, o questionamento acerca da legitimidade dos procedimentos seguidos pelos organizadores desses megaeventos e dos benefícios que de fato poderiam se reverter a favor da maioria da população por meio de sua realização, foram interpretados como obstáculos e como uma possível violação aos acordos assinados entre o governo brasileiro e o comitê organizador. Isto é, a repressão policial, inclusive com o uso de forças de 
segurança nacional, além, por exemplo, de posições com a do judiciário mineiro, que concedeu uma liminar proibindo, de antemão, manifestações políticas, como as que vinham ocorrendo em 2013, são indicativos fortes das tensões entre os direitos fundamentais e os imperativos comerciais de consumo e lucro; entre o exercício político da cidadania no acesso ao espaço das cidades e a privatização desses mesmos espaços, privatização esta que estaria amparada pelos acordos com o poder público, admitindo até o uso do discurso de ordem, segurança e eficiência.

\section{Iluminando o Problema: quando a participação democrática é posta na berlinda}

Segundo Jerome Valcke, Secretário-Geral da Federação Internacional de Futebol (FIFA), refletindo sobre a relação entre certos imperativos democráticos e constitucionais e o espaço exigido pela FIFA para a realização de seu evento máximo, enfatizou que, em sua interpretação, a Copa de Mundo de Futebol seria modelada e configurada em ambientes em que o exercício do poder estivesse menos submetido aos princípios democráticos. Por exemplo, para o referido membro da FIFA, a Copa do Mundo de Futebol da Rússia, a ser realizada em 2018, será mais "tranquila”, pois a tradição centralizadora russa, com menor abertura a questionamentos por parte da sociedade, ajudará a evitar manifestações como as ocorridas no Brasil, o que tornará menos problemático os preparativos e a operacionalidade da Copa de Futebol.

Em resumo, para um evento esportivo da magnitude da Copa do Mundo de Futebol, a descentralização do exercício do poder, a possibilidade de contestações e divergências públicas, ainda mais quando aliadas a formas republicanas e federativas de Estado e Governo, podem apresentar-se como elementos de desestabilização, obstáculos para a eficiência e a celeridade exigidas pelos organizadores desta mesma Copa de Futebol.

Nas palavras do Secretário-Geral do principal organismo do futebol mundial, 
[...] menos democracia, às vezes, é melhor para se organizar uma Copa do Mundo. Quando você tem um chefe de Estado forte, que pode decidir, assim como Putin poderá ser em 2018, é mais fácil para nós, organizadores, do que um país como a Alemanha, onde você precisa negociar em diferentes níveis ${ }^{1}$.

Nesta mesma linha de pensamento, Joseph Blatter, presidente da FIFA, além de concordar com Valcke, acrescentou, ao relembrar sua primeira experiência trabalhando na organização do maior torneio mundial de futebol, que, na sua perspectiva, a Copa de 1978, disputada na Argentina no período de regime ditatorial, foi como uma "[...] reconciliação do povo argentino com o sistema políticomilitar vigente na época”.

Ora, se assumir que democracia constitucional é o espaço do diálogo, do pluralismo, do compartilhamento de visões de mundo, de uma abertura ao diferente, onde o direito fundamental de participar ativamente dos processos de tomadas das decisões é garantido, ainda que potencialmente, a todos os cidadãos, sendo um meio de legitimação dessas mesmas decisões, como se pode interpretar ou traduzir as declarações dos altos representantes da FIFA já expostas? ${ }^{2}$

Em outras palavras, como ficam, por exemplo: a livre manifestação, a liberdade de expressão ou, até mesmo, a livre concorrência,

1 Tais declarações repercutiram fortemente na imprensa, tanto a nacional quanto a estrangeira. Nesse sentido, conferir, entre tantos sites que noticiaram e debateram as afirmativas de Valcke, nestes: <http://esportes.terra.com.br/futebol/valcke-menosdemocracia-ajudaria-na-organizacao-da-copa,e881 cdd88a83e310VgnCLD200000 0ec6eb0aRCRD.html >; $\quad<$ http://www.lancenet.com.br/copa-do-mundo/democraciaorganizar-Copa-Mundo-Valcke_0_907109447.html>; <http://www.bbc.co.uk/sport/0/ football/22288688>; $\quad<$ http://www.reuters.com/article/2013/04/24/us-soccer-fifaidUSBRE93N18F20130424>. Acessos em: 23 jul. 2013.

2 Neste ponto, é preciso recuperar uma observação realizada por Menelick de Carvalho Netto (2003, p. 126), a qual guia algumas de nossas análises, qual seja: “[...] não há e não pode haver nenhuma constitucionalidade no uso autoritário do constitucionalismo. O constitucionalismo não é e não pode ser neutro no que toca a privatização do público, é necessariamente plural e incorporador de complexidade. Portanto, é sempre uma força contrária às apropriações autoritárias do poder presentes em maior ou menor grau nas várias tradições nacionais." 
em um ambiente como o desenhado pelo denominado "padrão FIFA"? Tais princípios centrais dos modernos Estados Democráticos de Direito ficariam como que "suspensos" durante a realização das copas do mundo de futebol?

Procurando trabalhar tais questionamentos, entende-se ser necessário ressaltar que, na atualidade, eventos como a copa do mundo de futebol encontram-se inseridos dentro de uma lógica essencialmente econômica e financeira do fenômeno da globalização, fenômeno este que atingiu fortemente a noção de soberania dos Estados nacionais, os quais passaram a ver sua autonomia decisória ser desafiada por uma ordem internacional conformada, em grande medida, pelos interesses de gigantescas corporações e grupos empresariais, onde limites democraticamente estabelecidos são entendidos como obstáculos anacrônicos ao aumento, por exemplo, da taxa de lucratividade dos atores econômicos envolvidos nos vários megaeventos existentes.

Flávia Piovesan (2002), analisando a tensão entre uma globalização exclusivamente econômica e os movimentos que procuram "reforçar a democracia e os direitos humanos", desenvolve um argumento que não pode ser aqui desconsiderado, qual seja:

[...] o impacto transformador e desagregador da transnacionalização dos mercados sobre as estruturas político-institucionais, na medida em que as decisões passam a ser tomadas no âmbito de organismos multilaterais e conglomerados multinacionais, com a substituição da política pelo mercado, enquanto instância decisória. (PIOVESAN, 2002, p. 67, grifos nossos)

Dito de outro modo, temas, como os aqui abordados, não devem desconhecer

[A] força dos conglomerados transnacionais, o surgimento de esferas de decisão política e econômica em torno das diversas pessoas jurídicas de direito internacional público, grupos de Estados ligados por interesses comuns e consórcios regionais, além da hegemonia do pensamento econômico liberal, vêm esvaziando as democracias 
e conseqüentemente retirando poder de seus cidadãos. (VIEIRA, 2002, p. 450)

Nesta mesma linha argumentativa, é possível afirmar que esse processo de globalização econômica conduz a uma paulatina transferência do exercício do poder decisório para instituições e organismos internacionais, sejam eles como a Organização das Nações Unidas, a Organização Mundial do Comércio, o Banco Mundial ou o Fundo Monetário Internacional, ou entidades essencialmente guiadas por interesses privados, por exemplo, a Fédération Internationale de Football Association, uma associação suíça de direito privado ${ }^{3}$.

Fazendo um rápido parênteses, pode-se aferir que uma "globalização" que se restringe a criar "facilitadores" para os empreendimentos, desconhece todo o potencial emancipador e legitimador existente em democracias constitucionais como a aqui pressuposta, pois a dimensão dialógica que estas mesmas democracias implicam passa a ser entendida como um entrave. Como afirmava e advertia Milton Santos (1994, p. 35), ao criticar tais vertentes, seria possível dizer que, "monológicas" de globalização, "[...] as tentativas de construção de um só mundo sempre conduziram a conflitos, porque se tem buscado unificar e não unir".

Aliado a essas circunstâncias, há também uma série de denúncias referentes a desapropriações e deslocamentos que estariam sendo efetivados, em nome das obras de infraestrutura para a copa do mundo, em uma quase completa ausência de diálogo efetivo com os grupos sociais atingidos, em que, por exemplo, inúmeros projetos executivos das citadas obras estão sendo realizados sem uma oitiva pública que transcenda a mera formalidade determinada pela lei, isto é, verifica-se, de acordo com vários

3 Conferir, nesse sentido, entre outros: Anderson (1995), Bauman (1999), Chesnais (2004) e Chossudovsky (2000). 
informes, que a exigência de um debate prévio está sendo substituída por notificações meramente formais de decisões já tomadas por experts ${ }^{4 / 5}$.

Em outros termos, o que se verifica é um progressivo e por demais perigoso esvaziamento da noção de participação efetiva por meio dos canais de comunicação constitucionalmente previstos, levando a uma descrença institucional generalizada, pois o cidadão se vê como desprovido de qualquer capacidade efetiva de influir nos processos decisórios de assuntos que lhe dizem respeito, onde o déficit de diálogo na implementação das políticas públicas é agravado por uma exclusão social historicamente presente. Eventos esportivos da magnitude de uma copa do mundo de futebol, ou uma olimpíada, destamparam conflitos e tensões latentes presentes na sociedade brasileira, sendo que temas essenciais como participação popular, modelos de democracia, soberania nacional e reformas estruturais, dentre outros, não são mais capazes de serem "solucionados" por uma espécie de tecnocracia que procura substituir e ocupar o espaço da cidadania na "gerência" do Estado.

Nessa linha, em que a participação popular é substituída por "especialistas", é que se visualiza, por exemplo, o fato de que o futebol, antes visto como uma "festa" desenrolada nas "gerais, populares e arquibancadas de estádios" é também, ele próprio, substituído pelo "fetiche moderno do espe-

\footnotetext{
4 Ver, entre outras, nestes sites: <http://www.abc.com.py/internacionales/onu-preo cupada-por-denuncias-de-desalojos-en-brasil-584318.html $>$; $\quad<$ http://pfdc.pgr.mpf.gov. br/atuacao-e-conteudos-de-apoio/publicacoes/direito-a-moradia-adequada/revistas/copa2014-olimpiadas-2016-e-megaprojetos-remocoes-em-curso-no-brasil/view $>$ e $<$ http:// www.prmg.mpf.gov.br/imprensa/noticias/direitos-do-cidadao/copa-2014-mpf-questionaremocao-forcada-de-moradores-da-rua-lotus-em-belo-horizonte-mg>. Acessos em: 17 jun. 2013.

5 Consultem-se ainda os relatórios de pesquisa do Programa Pólos de Cidadania, da Faculdade de Direito da UFMG. Os efeitos do Vila Viva Serra na condição socioeconômica dos moradores afetados, orientado pelo Professor Doutor Márcio Túlio Vianna e financiado pelo Cnpq; e Estado, Regulação e Território na Região Metropolitana de Belo Horizonte: intervenções urbanística e organização do espaço nos vetores norte e sul da $R M B H$, orientado pela Professora Doutora Maria Fernanda Salcedo Repolês e financiada por meio de convênio, pela Agência Metropolitana de Belo Horizonte, Sedru e Fundep, disponíveis em: <www.polosdecidadania.com.br $>$. Consultar ainda o documentário Uma avenida em meu quintal, disponível em: <http://youtube/rlxKVtikzPw>.
} 
táculo" (DEBORD, 1997), o qual passa a ocorrer nas "cadeiras numeradas das novas arenas" localizadas dentro de espaços geográficos organizados a partir de uma ótica da "eficiência higienista", do "exclusivo", marcadamente excludente, onde poucos têm acesso a tais "territórios".

\section{O "Território FIFA", a Constituição da República de 1988 e 0 Sentido da Soberania}

Tendo como pano de fundo as ressalvas do ponto anterior, sinteticamente elencadas, é que se indaga sobre uma possível inadequação constitucional da denominada Lei Geral da Copa (Lei n. 12.663/2012), a qual, em princípio, estaria quase que "suspendendo" algumas garantias e direitos fundamentais elencados na Constituição de 1988, além de colocar em "xeque" a própria noção e alcance da soberania nacional.

A título ilustrativo, pode-se realçar o artigo 11 da citada legislação da copa do mundo, o qual estabelece uma espécie de zona exclusiva de comércio, em que é assegurado à entidade organizadora e aos seus patrocinadores indicados autorização para, sem concorrência, explorar em todas as dimensões, atividades comerciais na área dos chamados locais oficiais de competição, atingindo, até mesmo, o comércio ocorrido nas ruas entorno de tais locais.

Essa área de exclusividade poderá, segundo a mesma lei, ser estabelecida a partir de requerimentos oriundos da FIFA ou de terceiros indicados por tal entidade do futebol mundial, sendo o perímetro de tal ZEC definido no máximo de dois quilômetros ao redor dos locais oficiais de competição.

$\mathrm{Na}$ esteira de tais disposições, foram tomadas algumas decisões que geraram, no mínimo, um enorme mal estar aos governos estaduais e federal, como, por exemplo, quando a FIFA determinou que as famosas baianas, as quais, diga-se, são tidas como patrimônio brasileiro pelo Ministério da Cultura, fossem impedidas de comercializar seus "quitutes" ao redor da Arena Fonte Nova, em Salvador, durante a Copa das Confederações, já que existe uma vedação, por parte da mesma FIFA, de que patro- 
cinadores "oficiais", como a rede McDonald's, sofressem "concorrência" na área "exclusiva" de dois quilômetros.

Após uma série de manifestações e de uma resistência civil organizada por parte da Associação das Baianas de Acarajé e Mingau, que incluiu até mesmo a entrega de uma carta dirigida à Presidenta Dilma, além da colheita pública de assinaturas em favor de suas reivindicações, as baianas foram, ainda que parcialmente, vitoriosas, pois a FIFA decidiu "liberar" - aqui já presenciamos uma redefinição do âmbito normativo do sentido da soberania - a presença de um número que ainda será definido dessas vendedoras tradicionais da cultura da Bahia ao redor da Fonte Nova, ou seja, uma entidade privada internacional resolveu quem pode e quem não pode adentrar em suas "fronteiras", no "território FIFA"'. Proibições similares aconteceram em outras cidades brasileiras sede da Copa das Confederações. Em Belo Horizonte, por exemplo, os vendedores de "feijão tropeiro" foram proibidos de comercializar a iguaria regional sob os mesmos argumentos.

Saliente-se, também, que essas "fronteiras"- perímetro de dois quilômetros em torno das arenas de futebol - foram palco das passagens mais tensas e conflituosas das manifestações populares de protesto ocorridas durante o decorrer da Copa das Confederações, com confrontos que, infelizmente, deixaram marcas graves e profundas, indo além dos danos materiais, causando, inclusive, mortes em Belo Horizonte, além de inúmeros feridos ${ }^{7}$.

$\mathrm{Na}$ esteira de tal argumentação, várias indagações têm sido levantadas sobre certas disposições da lembrada Lei Geral da Copa, por exemplo, as normas presentes nos capítulos III e IV desta lei, os quais se referem, respectivamente, aos procedimentos de emissão de vistos de entrada e permissões de trabalho e da responsabilidade civil da União durante a

6 Conferir em: <http://www1.folha.uol.com.br/esporte/folhanacopa/2013/06/1289865fifa-recua-e-libera-baianas-do-acaraje-na-fonte-nova.shtml>. Acesso em: 23 jul. 2013.

7 Ver em: <http://noticias.r7.com/minas-gerais/viaduto-da-morte-em-bh-deixa-cincoferidos-e-um-morto-em-protestos-contra-a-copa-27062013>. Acesso em: 23 jul. 2013. 
realização da Copa do Mundo perante a FIFA, os quais nos remetem ao sentido da soberania estatal diante de uma entidade privada ${ }^{8}$.

É possível realçar, também, por uma questão de coerência com os pressupostos que norteiam as nossas análises, que a Lei n. 12.663, de 5 de junho de 2012, em seu artigo 28, parágrafo $1^{\circ}$, quando aborda o "acesso e a permanência" no "território FIFA", ressalva e garante o direito constitucional a livre manifestação e à plena liberdade de expressão em defesa da dignidade da pessoa humana.

Entretanto, ressalta-se que tal normativa, diante de alguns fatos ocorridos no transcorrer da Copa das Confederações (evento teste prévio a Copa do Mundo), aparenta, em princípio, ter sido limitada ao lado externo da fronteira de dois quilômetros da área "administrada" pela Fédération Internationale de Football Association, o que nos remete, novamente, ao nosso texto constitucional, o qual não estipula tais limites territoriais, objetivamente dispostos, como condição de possibilidade do exercício do direito fundamental de reuniões e manifestações pacíficas.

Seguindo tal linha crítica diante da referida legislação geral da copa do mundo, a Procuradoria Geral da República impetrou uma $A c ̧ a ̃ o ~ D i-$ reta de Inconstitucionalidade (ADI 4976) no Supremo Tribunal Federal (STF), arguindo que, na perspectiva da PGR, alguns artigos da Lei da Copa do Mundo seriam inconstitucionais por afrontarem, por exemplo, o princípio da igualdade, constitucionalmente assegurado, o qual veda distinções arbitrariamente feitas entre brasileiros.

Como aqui já lembrado, também o Ministério Público Federal questionou, por exemplo, o artigo 23 da Lei n. 12.663/2012, que determina que a União terá que assumir a responsabilidade civil perante a entidade organizadora (FIFA) e outros na legislação dispostos, por qualquer ação ou omissão, acidente ou incidente, relacionados a Copa do Mundo e sua realização.

Na ADI 4.976, o MPF afirma que o disposto sobre responsabilidade civil da União, no art.23 da Lei da Copa, teria adotado a chamada Teoria

8 Em relação ao sentido de soberania no processo histórico, conferir em: Neuenschwander Magalhães (2000). 
do Risco Integral, pois determinaria que a União assumisse a responsabilidade civil por danos ainda que não causados por seus "agentes", o que confrontaria a norma contida do artigo 37 , parágrafo $6^{\circ}$ da Constituição da República de $1988^{9}$, o qual teria abraçado a Teoria da Responsabilidade Objetiva, isto é, o texto constitucional não admitiria a ideia do "risco integral", pois se há responsabilidade objetiva prescinde da aferição da presença ou não de dolo ou culpa, nem por isso afasta a necessidade da conduta danosa ter sido praticada por um "agente público". ${ }^{10}$

Além do referido dispositivo legal, acima analisado, a ProcuradoriaGeral da República, na mesma ADI 4.976, também questiona o artigo 53 do mesmo diploma legislativo, o qual estipula a isenção concedida a FIFA, as suas subsidiárias no Brasil, assim como aos seus representantes legais,

[...] do adiantamento de custas, emolumentos, caução, honorários periciais e quaisquer outras despesas devidas aos órgãos da Justiça Federal, da Justiça do Trabalho, da Justiça Militar da União, da Justiça Eleitoral e da Justiça do Distrito Federal e Territórios, em qualquer instância, e aos tribunais superiores, assim como não serão condenados em custas e despesas processuais, salvo comprovada má-fé.

Na perspectiva da PGR, a norma contida no artigo 53 desconheceria o princípio da igualdade ou isonomia tributária, o qual, na dicção do artigo 150, inciso II, do texto constitucional de 1988, veda à União

[...] instituir tratamento desigual entre contribuintes que se encontrem em situação equivalente, proibida qualquer distinção em razão de ocupação profissional ou função por eles exercida, independentemente da denominação jurídica dos rendimentos, títulos ou direitos.

\footnotetext{
9 Art.37 Parágrafo $6^{\circ}$ da Constituição Federal de 1988, in verbis: As pessoas jurídicas de direito público e as de direito privado prestadoras de serviços públicos responderão pelos danos que seus agentes, nessa qualidade, causarem a terceiros, assegurado o direito de regresso contra o responsável nos casos de dolo ou culpa. (Grifos nossos)

10 Ver em: ADI 4.976, disponível no Site do Supremo Tribunal Federal <http://www. stf.jus.br/portal/peticaoInicial/verPeticaoInicial.asp?base=ADIN\&s $1=4976 \&$ proces so=4976>. Acesso em: 12 ago. 2013.
} 
Na referida ação direta de inconstitucionalidade, a mesma PGR entende que não há motivos que justifiquem tal tratamento diferenciado, o qual seria desprovido de base de legitimação constitucionalmente adequada, onde, por exemplo, a citada isenção concedida a FIFA e seus representantes legais seria, em realidade, um "favorecimento ilegítimo", isto é, não haveria, no caso concreto, uma justificativa lógica que compatibilizasse tal isenção com o princípio, constitucionalmente previsto, de isonomia tributária, como acima exposto ${ }^{11}$.

Ora, com base em todos os argumentos até neste ponto elencados, ainda que de modo sabidamente sintético, pode-se denotar que, em princípio, tais medidas e instrumentos legais concretizam uma redefinição do que seja soberania nacional e, por consequência, também redefinem os mecanismos de debate de vários temas presentes na agenda pública, como, por exemplo, entre tantos, o deslocamento populacional urbano ocasionado pelas obras de infraestrutura necessárias a copa do mundo, assim como a transparência sobre o orçamento destinado a estas mesmas obras.

Desde já salienta-se que não se está, em hipótese nenhuma, propugnando um retorno ao significado tido como tradicional de soberania, no qual, grosso modo, o Estado tudo pode diante dos seus "súditos-cidadãos", os quais não têm direitos diante do aparato estatal, mais apenas deveres. Se reconhece, por exemplo, a força vinculante do denominado direito internacional dos direitos humanos e de todos os seus reflexos na ampliação dos sistemas internacionais de proteção dos direitos fundamentais dos indivíduos enquanto sujeitos de direito plenos.

Nessa perspectiva, o âmbito da soberania dos Estados é redimensionado, todavia não pela imposição de entidades exclusivamente privadas, norteadas tão somente pelos interesses de empreendimentos mercadológi-

11 Além dos referido dispositivos legais, já analisados, a Procuradoria-Geral da República, na mesma ADI 4976, também questiona o artigo 37 e a constitucionalidade da concessão de pagamentos e auxílios aos ex-jogadores campeões do mundo que estejam "sem recursos ou com recursos limitados". Para a Procuradoria da República, o artigo 37 afrontaria o princípio "geral” da igualdade, o qual proíbe, grosso modo, discriminações de tratamento entre os indivíduos que não sejam justificadas e legitimadas por favorecerem projetos, ações ou gastos de interesse da coletividade. 
cos, mais sim pelo diálogo multilateral existente na agenda internacional, onde "[...] o conceito de cidadania se vê, assim, alargado e ampliado, na medida em que passa a incluir não apenas os direitos previstos no plano nacional, mas também direitos internacionalmente enunciados" (PIOVESAN, 2012, p. 81). Desse modo, a concepção de soberania aqui adotada reconhece e incorpora o pluralismo democrático, afirmando o princípio da liberdade e da igualdade de expressão e participação na esfera pública, onde a crescente presença da defesa internacional dos direitos fundamentais da cidadania redefine a clássica visão de uma soberania "absoluta", a qual não mais se coaduna com discursos que procuram efetivar os direitos humanos, sendo que é este sentido "novo" de soberania, por exemplo, que nos possibilita questionar certas "falas" emitidas por organismos como a FIFA.

Ressalte-se, assim, que esta visão de uma espécie de "soberania de um território FIFA", com todos os resultados que daí possam advir, não se fundamenta no sentido de soberania por nós assumido, qual seja, aquela perspectiva de uma noção de soberania guiada dialogicamente pela busca de efetividade, no cenário nacional e internacional, dos direitos humanos e fundamentais dos cidadãos, entendidos estes não apenas como "consumidores ou clientes", mais sim, sujeitos de direito pleno, fazendo com que qualquer decisão só se legitime pela participação, pela possibilidade, democrática e constitucionalmente garantida, de expressar, publicamente, sua discordância e seu descontentamento pelo modo como as decisões são tomadas e implementadas, pois, no atual momento histórico - institucional que se move como nação, “[...] não há mais como cogitar da liberdade divorciada da justiça social, como também é infrutífero pensar na justiça social divorciada da liberdade". (PIOVESAN, 2000, p. 148)

Alia-se a isso o fato de que há neste cenário um profundo deslocamento do poder decisório para entidades internacionais privadas guiadas tão somente pelo lucro de "seus" investimentos, reduzindo a força normativa dos debates e das políticas "locais", gerando graves reflexos sociais no já historicamente injusto quadro social brasileiro, ou seja, em um Estado Democrático de Direito, como o conformado pela Constituição da República de 1988, as decisões requerem, para sua legitimação, que os seus destinatários tenham, ao menos, a possibilidade de se fazerem "escutar" e influir nos processos decisórios, reconhecendo-se como coautores destas 
mesmas normativas, onde o espaço público não pode ser reduzido ao "estatal", sob pena de uma privatização, ainda que dissimulada, desta mesma esfera pública.

"Privatizar" o espaço público entendido aqui como um agir orientado estrategicamente, para se apropriar de uma noção habermasiana (HABERMAS, 1989), visando, grosso modo, a obtenção do "sucesso" ou "eficiência" a partir de ações pautadas, principalmente, por cálculos do tipo meios e fins, onde os atores sociais atuam egocentricamente, sendo as decisões tomadas monologicamente, negando a dimensão intersubjetiva que a democracia constitucional configura.

Como o próprio Habermas escreve e realça, ao buscar distinguir o agir estratégico do agir comunicativo,

[E]m ambos os casos, a estrutura teleológica da ação é pressuposta [...] mas o modelo estratégico da ação pode se satisfazer com a descrição de estruturas do agir imediatamente orientado para o sucesso, ao passo que o modelo do agir orientado para o entendimento mútuo tem que especificar condições para um acordo alcançado comunicativamente sob as quais Alter pode anexar suas ações às do Ego. (HABERMAS, 1989, p. 165)

Além disso, a privatização da esfera pública denota a constituição de ações imunes à problematização e ao discurso. É nesse "tom" que Habermas explica a diferença entre esfera pública e esfera privada, não como "espaços" ou "lugares" e sim como temas que estão sujeitos à justificação coletiva e política de suas pretensões e àqueles que estão eximidos desse encargo. É o sentido da privatização que se procura imprimir à constituição do "território FIFA". A sua delimitação como zona econômica exclusiva decorrente de acordos comerciais teria que se submeter aos controles sociais, considerado o nível de complexidade e de envolvimento de financiamento público. Mas não bastasse abstrair dessa denominação o debate público, busca-se ir além e definir o território como zona de segurança pública controlada pelas forças de segurança nacional - as razões de Estado eximindo que se questione até mesmo a violência policial e a ação 
de violação de direitos fundamentais e de direitos humanos internacionais sobre esse território.

Com fundamento nessas concepções e sentidos de ação é que se pode afirmar que certas normas presentes na denominada Lei Geral da Copa podem potencializar tal privatização do público, haja vista que a legitimidade dessas mesmas normas é posta em dúvida pelo fato de que os seus destinatários - leia-se, a sociedade civil - não participaram (ou participem) efetivamente do processo decisório que conduziu (ou conduz) a elaboração ou a aplicação destes dispositivos legais, negando a dimensão de autolegislação, na qual os cidadãos não são apenas vistos como "receptores" passivos e alienados das normas que pretendem reger a nossa vida em comum, mais são, simultaneamente, copartícipes e coautores ativos da conformação da sociedade que habitam e desejam viver, onde legitimidade democrática é construída dialogicamente, vinculada que é a ideia de que "[...] só consente quem pode efetivamente discordar". (DUARTE, 2000, p. 250)

Em outras palavras, democracia constitucional, enquanto dimensão de uma legitimidade construída discursiva e intersubjetivamente (HABERMAS, 1997), pode se revelar, indubitavelmente, um "sério obstáculo", como destacou Jerome Valcke, mas não aos eventos em si mesmos considerados, como a copa do mundo de futebol, mais sim ao modo como esses mesmos empreendimentos esportivos são elaborados e realizados, a lógica estrita e restritamente mercadológica que os norteiam, a "ética padrão FIFA", pois espaços democraticamente estruturados realmente potencializam a crítica, possibilitando o desvelar e a problematização, por exemplo, da circunstância de que "[...] todos nós estamos condenados à vida de opções, mas nem todos temos os meios de ser optantes". (BAUMAN, 1999, p. 94)

\section{Conclusão}

É sempre importante recuperar, em estudos como os aqui empreendidos, a consideração realizada pelo Professor da Universidade de Brasília (UNB), Menelick de Carvalho Netto, o qual destaca que o “[...] 
pluralismo político e organizacional é essencial para que o público não seja privatizado por uma burocracia encastelada no poder" (CARVALHO NETTO, 2003, p. 156), argumento que possibilita, ao mesmo professor, anotar que "políticas públicas" são direitos da cidadania, "[...] mas somente o são, é claro, à medida que efetivamente promovam a liberdade e a igualdade dos membros da comunidade" (CARVALHO NETTO, 2003, p. 158), fazendo, mais uma vez, emergir a tensão constitutiva presente em qualquer questão constitucional.

Assim, contra a cada vez mais escancarada truculência, os paradoxos operam nos dois sentidos. Toda tentativa de controlar, de definir, de privatizar aquilo que é público opera contrafacticamente para o fortalecimento do direito não como um sistema de "lei e ordem" e sim como condição discursiva de efetividade e de legitimidade, como modo de reconstrução dos direitos humanos e da soberania. A violação do direito acaba sendo uma reafirmação do paradoxo e de sua força contrafactica ${ }^{12}$.

Denota-se, desse modo, e com base nas análises acima realizadas, ainda que de modo sintético, em razão do espaço e do tempo disponíveis, que por mais "fechadas", "precisas" e "técnicas" que as normativas referentes ao evento da FIFA pretendessem ser, buscando regular todos os espaços e especificidades dos ambientes e territórios afetados pela copa do mundo de futebol, a contingência presente no fenômeno jurídico foi exposta pela força das manifestações, manifestações estas que demonstraram o limite operacional do direito, tanto da justificação quanto da aplicação do ordenamento jurídico em contextos sociais cada vez mais complexos.

Em outros termos, a legislação da Copa do Mundo e todas as demandas por "justiça” presentes nas manifestações de junho de 2013 acabaram por demonstrar que a luta por interesses é distinta das batalhas por direitos, além de desvelar que lei alguma, por mais elaborada que seja, consegue prever todas as suas hipóteses de aplicação, nem controlar todas as reações que dessa mesma aplicação possam advir, isto é, um espaço do imprevisto, do não administrável, ainda mais em um Estado Democrático

12 Sobre a questão do direito como uma expectativa contrafactica de comportamento e do paradoxo constitutivo do mesmo, conferir, em uma perspectiva sistêmica, entre outros: Luhmann (1983), Campilongo (2000) e De Giorgi (1998). 
de Direito que se afirma plural, sempre lembra de que o risco e os limites funcionais são constitutivos do direito moderno. ${ }^{13}$

Percebe-se que há uma "disputa" de visões e representações de mundo, do significado de sociedade, de democracia e soberania, em que a ampliação dos debates e a maior transparência das esferas decisórias são traduzidos como "obstáculos" para a otimização da eficiência, sendo legitimidade reduzida a legalidade, gerando por consequência um "déficit de legitimação", ou seja, "[...] o círculo dos que participam de decisões democráticas não coincide exatamente com o circulo dos atingidos por aquelas decisões". (HABERMAS, 2003, p. 107)

Desse modo, a democracia constitucional pode ser realmente um enorme "incômodo" para empreendimentos impositivos, de "discurso único", pois a mesma potencializa a dimensão produtiva da contingência, desvelando a tensão entre liberdade e igualdade, onde a legitimidade é discursivamente construída em arenas públicas ampliadas, as quais forçam todas as "fronteiras" dos territórios artificialmente erigidos, onde pretensões são levantadas por "cidadãos", não apenas "clientes e consumidores."

Em suma, em ambientes democráticos e constitucionais, os "Estados devem promover e assegurar a livre, significativa e ativa participação de indivíduos e grupos na elaboração, implementação e monitoramento de políticas de desenvolvimento" (PIOVESAN, 2012, p. 159), haja vista ser esse o único caminho legitimador das decisões e ações concretizadas pelos poderes governamentais.

Dando primazia a uma concepção dialógica de democracia, na qual o sentido de soberania está intimamente vinculado ao ideário contemporâneo do direito internacional dos direitos humanos, também este marcado

\footnotetext{
13 Reconhece-se que "[...] é possível se utilizar de um discurso principiológico constitucional para defender e justificar violação de direitos. Esse é um risco inerente ao processo dialógico e ao pluralismo. Porque inerente, o risco pode ser administrado, mas não eliminado. Contamos com que esse mesmo risco que permite uma "apropriação indébita" da Constituição é o mesmo que nos obriga a admitir que ela é construída por um processo aberto a novos sujeitos e a novos conflitos e que estes podem também se utilizar dos princípios em favor da edificação de uma sociedade "livre, justa e solidária". (SALCEDO REPOLÊS, 2013, p. 225)
} 
pela abertura discursiva, onde legitimidade caminha ao lado da noção de autolegislação e do direito fundamental de discordar, é que se pode aferir, nos apropriando livremente de Hannah Arendt (ARENDT, 2001, p. 126) que as "fronteiras" não são apenas áreas ou zonas que nos separam, mais também que nos aproximam, potenciais faixas de contato, o que, talvez, permita reconhecer que o denominado "território FIFA", como atualmente implementado, em razão de sua pretensa exclusividade e acesso restrito, tenha muito mais o feitio de um gueto moderno, local de isolamento, e não de encontros festivos como, por exemplo, os campeonatos de futebol pretendem ser.

\section{Referências}

ANDERSON, Perry. Balanço do neoliberalismo. In: SADER, E.; GENTILE, P. (Org.). Pós-neoliberalismo: as políticas sociais e o Estado democrático. Rio de Janeiro: Paz e Terra, 1995, p. 9-23.

ARENDT, Hannah. Entre o passado e o futuro. 5. ed. Trad. Mauro W. Barbosa de Almeida. São Paulo: Perspectiva, 2001.

BRASIL. Constituição (1988). 16. ed. São Paulo: Rideel, 2013.

BRASIL. Lei n. 12.663, de 05 de junho de 2012. Diário Oficial da

União, Brasília, DF, 6 de junho de 2012.

BRASIL. Supremo Tribunal Federal. Ação Direta de

Inconstitucionalidade 4976. Relator: Ministro Ricardo Lewandowski.

Disponível em: $<$ http://www.stf.jus.br/portal/peticaoInicial/

verPeticaoInicial.asp? base $=$ ADIN\&s1 $=4976 \&$ processo $=4976>$. Acesso em: 12 ago. 2013

BAUMAN, Zygmunt. Globalização: as conseqüências humanas. Trad. Marcus Penchel. Rio de Janeiro: Zahar Editores, 1999.

BAUMAN, Zygmunt. Tempos líquidos. Tradução Carlos Alberto Medeiros. Rio de Janeiro: Zahar Editores, 2007. 
BUSTAMANTE, Thomas da Rosa. A justiça como procedimento. In: AVRITIZER, Leonardo (Org.). Dimensões políticas da justiça. Rio de Janeiro: Civilização Brasileira, 2013.

CAMPILONGO, Celso Fernandes. O Direito na sociedade complexa. São Paulo: Max Limonad, 2000.

CARVALHO NETTO, Menelick de. Apresentação de Friedrich Müller. Legitimidade como conflito concreto do direito positivo. Cadernos da Escola do Legislativo, Belo Horizonte, MG, v. 9, n. 5, p. 7-37, jul.-dez., 1999.

CARVALHO NETTO, Menelick. Intervenção. In: COUTINHO, Jacinto Nelson de Miranda. Canotilho e a Constituição Dirigente. Rio de Janeiro: Renovar, 2003. p. 124-130.

CATTONI DE OLIVEIRA, Marcelo Andrade; GOMES, David Francisco Lopes; MACHADO, Felipe Daniel Amorim. Pensando o Direito e a Política com e contra Hannah Arendt e Carl Schmitt. Revista da Faculdade de Direito da Universidade Federal de Minas Gerais (Impresso), Minas Gerais. v. 55, p. 117-140, 2009.

CHESNAIS, F. O capital portador de juros: acumulação, internacionalização, efeitos economicos e políticos. In: CHESNAIS, F.

(Org.). A Finança mundializada: raízes sociais e políticas, configuração, consequências. São Paulo: Boitempo, 2004.

CHOSSUDOVSKY, Michel. A Globalização da pobreza: Impactos das Reformas do FMI e do Banco Mundial. Trad. Marylene Pinto Michael. São Paulo: Moderna, 2000.

DEBORD, Guy. A Sociedade espetáculo. Trad. Estela dos S. Abreu. Rio de Janeiro: Contraponto, 1997.

DE GIORGI, Raffaele. Direito, democracia e risco: vínculos com o futuro. Porto Alegre: Sergio Antonio Fabris, 1998. 263 p.

DUARTE, André. O Pensamento à sombra da ruptura: política e filosofia em Hannah Arendt. São Paulo: Paz e Terra, 2000. 
HABERMAS, Jürgen. Direito e democracia: entre facticidade e validade. Trad. Flávio Beno S. Rio de Janeiro: Tempo Brasileiro, 1997. (v. I)

HABERMAS, Jürgen. Consciência moral e agir comunicativo. Trad. Guido A. de Almeida. Rio de Janeiro: Tempo Brasileiro, 1989.

HABERMAS, Jürgen. Era das transições. Trad. Flávio Siebeneichler. Rio de Janeiro: Tempo Brasileiro, 2003.

KOZICKI, Katya. A interpretação do direito e a possibilidade da justiça em Jacques Derrida. In: FONSECA, Ricardo Marcelo (Org.). Crítica da Modernidade: diálogos com o direito. Florianópolis: Fundação Boiteux, 2005, p.129-143.

LUHMANN, Niklas. Sociologia do Direito I. Trad. Gustavo Bayer. Rio de Janeiro: Tempo Brasileiro, 1983.

NEUENSCHWANDER MAGALHÃES, Juliana. História semântica do conceito de soberania: o paradoxo da soberania popular. Tese de Doutorado em Filosofia do Direito. Belo Horizonte: FDUFMG, 2000. 424p.

PIOVESAN, Flávia. (Coord.). Direitos humanos, globalização econômica e integração regional: desafios do Direito Constitucional Internacional. São Paulo: Max Limonad, 2002.

PIOVESAN, Flávia. Temas de direitos humanos. 5. ed. São Paulo: Saraiva, 2012.

PROGRAMA Polos de Cidadania. Os efeitos do Vila Viva Serra na condição socioeconômica dos moradores afetados, orientado pelo Professor Doutor Márcio Túlio Vianna e financiado pelo Cnpq. Relatório de pesquisa. [2015]. Disponível em: $<w w w . p o l o s d e c i d a d a n i a . c o m . b r>$. Acesso em: 22 abr. 2015.

PROGRAMA Polos de Cidadania. Estado, regulação e território na Região Metropolitana de Belo Horizonte: intervenções urbanísticas e organização do espaço nos vetores norte e sul da RMBH. (Orientado pela Professora Doutora Maria Fernanda Salcedo Repolês e financiada por meio de convênio, pela Agência Metropolitana de Belo Horizonte, Sedru e Fundep. Relatório de pesquisa). [2015]. Disponível em: $<$ www. polosdecidadania.com.br>. Acesso em: 22 abr. 2015. 
PROGRAMA Polos de Cidadania. Uma avenida em meu quintal. (Documentário). [2015]. Disponível em: <http://youtube/rlxKVtikzPw>. Acesso em: 22 abr. 2015.

SALCEDO REPOLÊS, Maria Fernanda. O direito na teoria e o direito na prática com o reconhecimento de novos atores sociais. Revista da Faculdade de Direito da Universidade Federal de Minas Gerais (Impresso), Minas Gerais, v. JJ, p. 211-228, 2013.

SANTOS, Milton. Técnica, espaço, tempo: globalização e meio técnicocientífico informacional. São Paulo: Hucitec, 1994.

SITETERRA. [2013]. Disponível em: <http://esportes.terra.com.br/futebol/ valcke-menos-democracia-ajudaria-na-organizacao-da-copa,e881 cdd88a83 e310Vgn2000000ec6eb0aRCRD.html>. Acesso em: 23 jul. 2013.

SITE LANCE. [2013]. Disponível em: <http://www.lancenet. com.br/copa-do-mundo/democracia-organizar-Copa-MundoValcke_0_907109447.html>. Acesso em: 23 jul. 2013.

SITE BBC. [2013]. Disponível em: <http://www.bbc.co.uk/sport/0/ football/22288688>. Acesso em: 23 jul. 2013.

SITE REUTERS. [2013]. Disponível em: <http://www.reuters.com/ article/2013/04/24/us-soccer-fifa-idUSBRE93N18F20130424>. Acesso em: 23 jul. 2013.

SITE ABC. [2013]. Disponível em: <http://www.abc.com.py/ internacionales/onu-preocupada-por-denuncias-de-desalojos-enbrasil-584318.html>. Acesso em: 17 jun. 2013.

PROCURADORIA da Defesa do Cidadão. [2013]. Disponível em: <http://pfdc.pgr.mpf.gov.br/atuacao-e-conteudos-de-apoio/ publicacoes/direito-a-moradia-adequada/revistas/copa-2014olimpiadas-2016-e-megaprojetos-remocoes-em-curso-no-brasil/ view>. Acesso em: 17 jun. 2013.

PROCURADORIA da República. Minas Gerais. [2013]. Disponível em: $<$ http://www.prmg.mpf.gov.br/imprensa/noticias/direitos-do-cidadao/ copa-2014-mpf-questiona-remocao-forcada-de-moradores-da-rua-lotusem-belo-horizonte-mg>. Acesso em: 17 jun. 2013. 
FOLHA/UOL. [2013]. Disponível em: <http://www1.folha.uol.com.br/ esporte/folhanacopa/2013/06/1289865-fifa-recua-e-libera-baianas-doacaraje-na-fonte-nova.shtml>. Acesso em: 23 jul. 2013.

NOTÍCIAS R7. [2007]. Disponível em: $<$ http://noticias.r7.com/minasgerais/viaduto-da-morte-em-bh-deixa-cinco-feridos-e-um-morto-emprotestos-contra-a-copa-27062013>. Acesso em: 23 jul. 2013.

Maria Fernanda Salcedo Repolês é professora adjunta dos cursos de graduação e de pós-graduação da Faculdade de Direito da Universidade Federal de Minas Gerais, e pós-doutora em Direito pela Universidade Federal do Rio de Janeiro. E-mail:mariaf.salcedo@gmail.com

Endereço profissional: Universidade Federal de Minas Gerais, Faculdade de Direito, Av. João Pinheiro, 100. CEP: 30.130-180, Belo Horizonte, MG, Brasil.

Francisco de Castilho Prates é doutorando em Direito pela Universidade Federal de Minas Gerais. É mestre em Direito Constitucional pela UFMG.

E-mail: castilho_2011@yahoo.com.br.

Endereço profissional: Universidade Federal de Minas Gerais, Faculdade de Direito, Av. João Pinheiro, 100. CEP: 30.130-180, Belo Horizonte, MG, Brasil. 
